\title{
The Social Contagion of Antisocial Behavior
}

\author{
Milena Tsvetkova, Michael W. Macy
}

Cornell University

\begin{abstract}
Previous research has shown that reciprocity can be contagious when there is no option to repay the benefactor and the recipient instead channels repayment toward strangers. In this study, we test whether retaliation can also be contagious. Extending previous work on "paying it forward," we tested two mechanisms for the social contagion of antisocial behavior: generalized reciprocity (a victim of antisocial behavior is more likely to pay it forward) and third-party influence (an observer of antisocial behavior is more likely to emulate it). We used an online experiment with randomized trials to test the two hypothesized mechanisms and their interaction by manipulating the extent to which participants experienced and observed antisocial behavior. We found that people are more likely to harm others if they have been harmed and they are less likely to do so if they observe that others do not harm.
\end{abstract}

Keywords: social contagion; reciprocity; social influence; antisocial behavior; online experiments

Citation: Tsvetkova, Milena, and Michael W. Macy. 2015. "The Social Contagion of Antisocial Behavior." Sociological Science 2: 36-49.

Received: November 24, 2014

Accepted: January 5, 2015

Published: February 4, 2015

Editor(s): Jesper Sørensen, Gabriel Rossman

Dol: $10.15195 / \mathrm{v} 2 . \mathrm{a} 4$

Copyright: (C) 2015 The Author(s). This open-access article has been published under a Creative Commons Attribution License, which allows unrestricted use, distribution and reproduction, in any form, as long as the original author and source have been credited. (0)(1)
THE health regime we follow (Centola 2010), the music we listen to (Salganik,

Dodds, and Watts 2006), the new technologies we adopt (Rogers 2003), the news stories we read (Muchnik, Aral, and Taylor 2013), and even the likelihood that we vote in an election (Bond et al. 2012) are all to a large degree influenced by our friends and peers. Many human behaviors spread through social contact, including some that are often assumed to be acquired independently, such as obesity and fertility (Christakis and Fowler 2009).

Prosocial behavior has also been shown to be contagious. Fowler and Christakis (2010) found experimental evidence that if you help someone, you not only increase the likelihood that they help others, but that those they help will also help others, and so on, out to three steps. Suri and Watts (2011) and Jordan et al. (2013) similarly found that generous behavior is contagious, but that it does not spread beyond the direct interaction. Tsvetkova and Macy (2014b) identified two mechanisms through which prosocial behavior spreads: both those who benefit from prosocial behavior and those who observe prosocial behavior are more likely to behave prosocially towards strangers. The observation-based mechanism has additionally been confirmed in field experiments: witnessing one kind of prosocial behavior, such as picking up litter, increases the odds of performing another, such as picking up a fallen letter, picking up a fallen bicycle, or helping a stranger pick up dropped fruit from the ground (Keizer, Lindenberg, and Steg 2013).

Prosocial behavior confers a benefit to others that outweighs any personal cost. Previous research (Tsvetkova and Macy 2014a, 2014b) has shown that beneficiaries of positive prosocial behavior become more willing to pay these costs and less vulnerable to the bystander effect. As a consequence, prosocial behavior can ripple through networks. 
In contrast, antisocial behavior imposes costs on others that outweigh any personal benefit. Previous studies have shown that observation of socially irresponsible behaviors like littering (Cialdini 2008) and graffiti (Keizer, Lindenberg, and Steg 2008) can weaken the protective effects of social norms. If antisocial behavior is also contagious, a single act of misbehavior has the potential to trigger a chain reaction that reaches far beyond the original victims. The present study extends research on antisocial contagion by investigating the underlying causal mechanisms. In parallel with previous research on the diffusion of prosocial behavior (Tsvetkova and Macy 2014b), we investigate two possible mechanisms: generalized reciprocity and third-party influence. In particular, we focus on a definition of generalized reciprocity as pay-it-forward behavior that is distinct from indirect reciprocity and peer pressure. Using data from an online experiment with human subjects, we find that harming others increases after being harmed but decreases after observing low levels of antisocial behavior. In the discussion, we compare the contagion dynamics of prosocial and antisocial behavior and note important similarities and differences. We also discuss the practical implications of the findings for activists, policy makers, managers, and administrators tasked with developing effective strategies for reducing the incidence and normative acceptance of antisocial behavior.

\section{The Contagion of Antisocial Behavior}

Criminologists and scholars of deviance were among the first to argue that antisocial behavior can be contagious, based on observational data showing that violent crime tends to be individually reciprocated, collectively escalating, and spatially clustered (Loftin 1986). Researchers hypothesized that violent behavior can be transmitted between generations when individuals have been maltreated as children (Widom 1989) and within generations when criminal behavior is socially learned through communication and interaction (Sutherland and Luckenbill 1992), or when people who witness or experience violence retaliate or preempt it (Loftin 1986). While theories of social contagion are consistent with observed patterns, the correlational data cannot rule out alternative mechanisms such as a common external cause (Fagan, Wilkinson, and Davies 2007) or heredity (Jones and Jones 2000). A comprehensive review of observational studies shows that the empirical support for the interpersonal transmission of violent crime is contradictory and problematic (Widom 1989).

The empirical evidence for the contagion of antisocial behavior is more consistent for the spread of nonviolent crime, mainly coming from field tests of the broken windows theory (Wilson and Kelling 1982). The hypothesis is that minor infractions such as graffiti, litter, or broken windows can signal the absence of monitoring, enforcement, and public support of laws and social norms, leading to a self-reinforcing downward spiral (Keizer, Lindenberg, and Steg 2008). Thus, if people notice that others litter, they become more likely to litter themselves (Cialdini, Reno, and Kallgren 1990).

In addition to these field studies, antisocial contagion has also been studied using controlled experiments with monetary incentives. Falk and Fischbacher (2002) used a four-person stealing game to show that if people know that other members 
of their group steal, they become more likely to steal as well. Jordan et al. (2013) found that defection is contagious in a 20-person prisoner's dilemma game.

Although these studies have advanced knowledge of the contagious properties of antisocial behavior, they share an important limitation: the inability to distinguish between the effects of victimization and of observation. As a result, these studies cannot identify the underlying causal mechanism.

\section{Generalized Reciprocity and Third-Party Influence}

The present study extends previous research by investigating the relative importance and interaction of victimization and observation as mechanisms for the contagion of antisocial behavior among strangers. These two mechanisms-formalized as generalized reciprocity and third-party influence-have been shown to affect the contagion of prosocial behavior (Tsvetkova and Macy 2014b). Generalized reciprocity occurs when those who benefit from a stranger's prosocial behavior act more prosocially towards others in the future. Third-party influence occurs when those who observe prosocial behavior by strangers behave more prosocially towards strangers. Generalized reciprocity characterizes pay-it-forward behavior triggered by an affective response to receiving help (in contrast to indirect reciprocity and generalized exchange; see below), while third-party influence characterizes social learning through imitation of others' behavior.

Data from an online experiment (Tsvetkova and Macy 2014b) has shown that receiving help increases one's likelihood to help, but observing help does so only if the frequency of helping is sufficiently low. Indeed, helping behavior decreases as helping becomes more widespread. A possible explanation for this decrease is that once a prosocial norm has been established and people take for granted that someone else is likely to help, one's own contribution appears less essential. This effect is similar to the free rider problem in collective action, the problem of social loafing in work teams and small groups, and the bystander effect, or the diffusion of responsibility, in crowds. Nevertheless, the decrease in helping behavior does not occur for those who have benefitted from others' help. In other words, generalized reciprocity can offset the temptation to free ride when observing widespread prosocial behavior.

The findings suggest the possibility that similar mechanisms might underlie the contagion of antisocial behavior. If so, then we should expect those who are victims of antisocial behavior to pay it forward by "retaliating," not against the perpetrator but against innocent others, and by imitating the antisocial behavior of others. However, there is also an important asymmetry between prosocial and antisocial behavior. While widespread prosocial behavior can encourage the belief that one's own contributions are not needed, widespread antisocial behavior does not entail a similar free rider opportunity. We therefore do not expect the decreasing effects of third-party observation that were found for prosocial behavior. Instead, we expect that if antisocial behavior is rare, one may be less tempted to behave antisocially, while if antisocial behavior is rampant, one may feel licensed to behave more antisocially. 
An analogous difference should apply to the positive interaction between generalized reciprocity and third-party influence that was reported for prosocial behavior. Although generalized reciprocity was found to temper the tendency to free ride when prosocial behavior was sufficiently widespread, the inability to free ride on the antisocial behavior of others means that there is no bystander effect that generalized reciprocity might then be expected to attenuate. On the contrary, if the personal experience of being victimized weakens the normative acceptance of antisocial behavior, then the interaction may be negative rather than positive. Put differently, the directed (dyadic) antisocial act may no longer be taken personally, but attributed instead to a societal pattern. Further, when antisocial behavior is widely observed, victims may feel less motivated to "do unto others" antisocially.

\section{Generalized Reciprocity, Indirect Reciprocity, and Generalized Exchange}

It is important to note that generalized reciprocity, as that term is used here, should not be confused or equated with what sociologists and social psychologists have previously referred to as "indirect reciprocity" and "generalized exchange" (Ekeh 1974; Yamagishi and Cook 1993; Lawler 2001; Molm, Collett, and Schaefer 2007; Molm 2010). In the evolutionary biology and behavioral economics literature, the term "generalized reciprocity" is used to refer to helping behavior in which there is no opportunity to act on or respond to reputational information (Ben-Ner et al. 2004; Nowak and Sigmund 2005; Bartlett and DeSteno 2006; Nowak and Roch 2007; Stanca 2009). In contrast, indirect reciprocity and generalized exchange involve reputational mechanisms.

Our study is motivated in part by the need to isolate the effects of generalized reciprocity from reputation effects. Although previous research on indirect reciprocity and generalized exchange has focused exclusively on helping behavior, reputational effects can also influence harmful behavior, as a strategic deterrent and social sanction.

Previous research on indirect reciprocity examined the hypothesized effects of strategic considerations regarding one's reputation or "image-score" (Raub and Weesie 1990; Wedekind and Milinski 2000; Seinen and Schram 2006). Experimental tests of indirect reciprocity as a reputation effect typically use a design in which A interacts with $\mathrm{B}$, and then $\mathrm{C}$ (knowing how $\mathrm{A}$ treated $\mathrm{B}$ ) interacts with $\mathrm{A}$. In contrast, we use an experimental design in which $A$ interacts with $B$, and then $B$ interacts with $C$, which removes any possibility for reputational effects as an incentive or reward.

Our design also differs from experimental studies of generalized exchange, which typically allow repeated interactions in fixed network structures, where each actor receives from one group member but gives to another (Yamagishi and Cook 1993; Molm, Collett, and Schaeffer 2007; Molm 2010) and group members often have full information about all pairwise exchanges (Greiner and Levati 2005; Tsvetkova and Buskens 2013). This design allows participants to use generalized exchange not only to express feelings of obligation and gratitude in response to receiving help but also as a reputational strategy for obtaining help in the future 
and for rewarding those who have helped in the past. Similarly, well known cases of generalized exchange in naturally occurring environments are likely to include manifestations of reputation effects: the Kula trading ring among South Pacific islanders (Malinowski 1920), the kinship relations among aboriginal tribes (Bearman 1997), and the support networks of low-income black women (Uehara 1990).

Our research design also extends previous knowledge by studying generalized reciprocity in large networks, with the possibility for a pay-it-forward cascade of contagious malevolence. Even if antisocial behaviors are highly contagious, cascades are not possible with dyadic reciprocity, indirect reciprocity, or with generalized exchange in small groups with complete networks. In contrast, generalized reciprocity in open networks allows the possibility for ripple effects that magnify the negative effects of harming others, as the mirror image of the ripple effects from helping (Nowak and Roch 2007; Fowler and Christakis 2010).

In sum, motivated by the gaps in the literature on broken windows, indirect reciprocity, and generalized exchange, the present study aims to investigate the conditions under which antisocial behavior emerges and spreads in large groups through processes of victimization and observation, in the absence of reputationbased social controls.

\section{Materials and Methods}

To test the mechanisms, we conducted an online experiment. The experiment was called "The Bonus Game" and was conducted with 750 participants in March 2014. We used a power analysis (shown in Figure A1 in the online supplement) to confirm that the number of participants provided sufficient statistical power to test the hypotheses. Participants were recruited from and paid through the online crowdsourcing platform Amazon Mechanical Turk (AMT) but interacted on a website hosted on our webserver. The experiment was designed as a sequential game in which participant $i$ 's payment was determined by the amount the previous participant $(i-1)$ took from $i$ and the amount $i$ decides to take from the next participant $(i+1)$.

We recruited a large number of participants by posting a human intelligence task (HIT) on AMT. The HIT paid a small amount (\$0.25) for a ten-minute task, with the opportunity to earn up to $\$ 1.25$ as an additional bonus. The HIT asked AMT users to read and agree to the terms of the study and go to our website to complete the task. On our website, AMT users first had to provide their AMT worker ID and standard demographic information (gender, age, ethnicity, nationality, education, religious affiliation, and income). The instructions emphasized that the demographic information is not required and that it did not affect one's participation in the game. (For detailed demographics of the sample, see Table A4 in the online supplement.)

Second, AMT users had to read the instructions for the game and answer a short quiz. The game instructions explained to each participant that they were part of a chain of other participants. Each participant on the chain could decide to transfer either $\$ 0.00$ or $\$ 0.50$ from the next participant's earnings to themselves. The amount transferred from the next participant would be divided by two and added to the 
participant's bonus. The instructions further emphasized that all participants on the chain faced the same decision.

The AMT users then had to answer a five-question quiz that tested their understanding of the game instructions. If they correctly completed the quiz within three attempts, they earned a $\$ 0.50$ participation fee and proceeded to play the game with the potential to earn an additional bonus; otherwise, their participation ended and they were paid the base HIT rate.

The continuing participants were next given information about the amount transferred by the previous player and the effects of this on their earnings. The participants were then asked to make a decision about the amount to transfer from the next participant. Before they could submit their decision, participants were required to write a short summary to demonstrate that they understood the decision they were asked to make. In the observation condition, participants were also presented with information about the level of transfer by previous participants.

We refer to participants at the beginning of the chain as "seeds" and those who follow a seed as "links." The instructions and the decision situation were identical for seeds and links, with one exception. For seeds, a lottery was used to determine the amount to be transferred from their earnings. For links, the amount was determined by the previous participant. We referred to the previous participants by their randomly anonymized AMT worker IDs in order to dispel any suspicion of deception and to make the information more compelling (as detailed in the online supplement).

In short, we implemented two between-individual manipulations:

- Whether the participant's payment was affected by a transfer by another participant (links) or determined by a lottery (seeds). The experiment did not involve deception, and the instructions explained the source and amount of this transfer differently, depending on whether the participant was a seed or a link.

- Whether the participant was able to observe the level of transfers by others (observation condition) or not (no-observation condition). Since the experiment did not involve deception, the level of transfers the participant observed varied depending on the decisions made by previous participants.

The observation condition provided summary information on the percentage of others who elected to transfer $\$ 0.50$. In order to guarantee enough variation in the observed transfer levels, we limited the window of observation to a small but meaningful unit in the population - the chain, defined as a sequence of participants who each take from the next in line. However, in order for seeds to observe others, it was necessary that participants observe at least one other chain apart from their own.

We manipulated observation levels by varying which chains the participant was able to observe. Participants were randomly assigned to either of two observation groups, in which they observed the transfer rates in chains that were randomly selected with a probability corresponding to the percentage who chose to transfer $\$ 0.50$. We needed four chains to ensure sufficient variation in the transfer rates that participants observed. 


\section{A) Seeds}

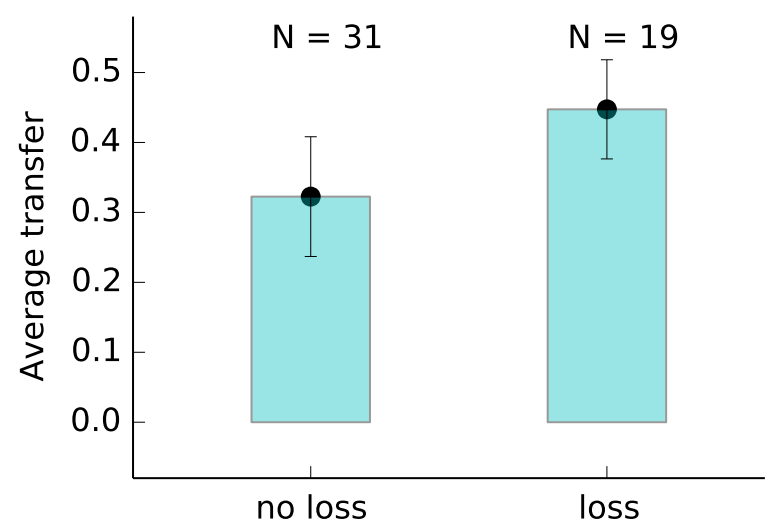

B) Links

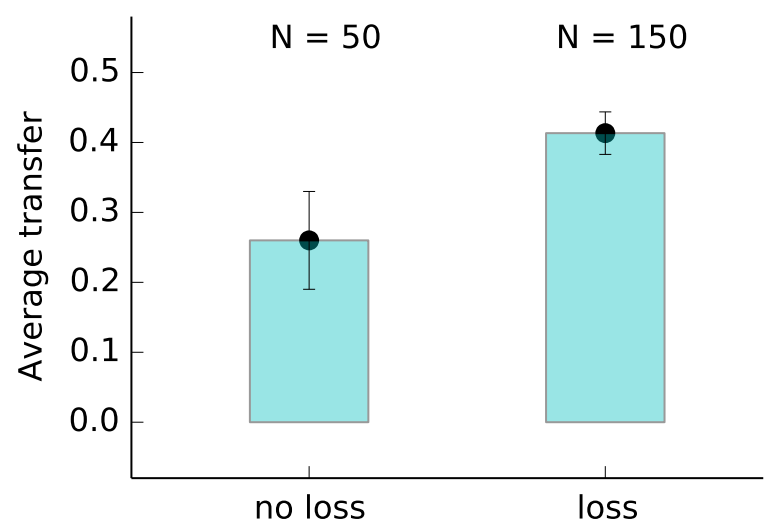

Figure 1: The effect of generalized reciprocity on the amount transferred from the next participant. The figure shows the mean transfer rate and 95\% confidence interval for A) seeds and B) links in the noobservation condition, along with the number of observations in each condition. The figure shows higher transfer rates among those who have experienced a loss but the differences are statistically significant only among links, whose loss was imposed by the actions of another participant.

We did not reveal the number of previous participants over which the transfer level was estimated in order to avoid potentially confounding normative behavior (of the average individual) with the effects of knowledge about the length of chains or the current participant's position. (These would also be potentially important treatment conditions in a chain-level analysis, which we leave for future research). Neither did we inform participants about the possible or actual length of chains or about their position in the chain, since this information might confound the effects of the observation of transfers. For example, knowing that one is at the end of a long chain conveys information about the normative behavior of others. Because this study did not use chain length as either a treatment or an outcome measure, we were able to limit the length of chains in order to ensure the necessary distribution of seeds and links. (Without any limit, it would be theoretically possible to end up with a single chain, with only one seed and everyone else a link.) We limited the chains to four links.

The no-observation/low-observation/high-observation manipulations defined three treatment groups. A number of chains were started in each of the groups, and participants were randomly assigned to one of these chains. If participants happened to be the first on the chain, they were treated as seeds, otherwise as links.

To isolate the effects of generalized reciprocity and third-party influence, we tested generalized reciprocity in the no-observation condition (Figure 1), and we tested third-party influence among those with no loss (Figure 2). In addition, we conducted separate analyses for seeds and links in order to distinguish between the response to losses imposed by chance and those imposed by another participant. 
Table 1: The effect of generalized reciprocity on the amount transferred from the next participant.

\begin{tabular}{lcc}
\hline & Seeds & Links \\
\hline Loss & $1.542^{\dagger}$ & $1.482^{\dagger}$ \\
Constant & $(0.837)$ & $(0.356)$ \\
& 0.598 & 0.080 \\
Number of observations & $(0.375)$ & $(0.283)$ \\
LR $\chi^{2}(1 d f)$ & 50 & 200 \\
\hline
\end{tabular}

Note: The table reports coefficients and standard errors (in brackets) from logistic regressions for Seeds and Links in the no-observation treatment. Results show that participants who experience a loss are more likely to impose a loss on others, but the difference is statistically significant only among links.

Two-sided tests: $* p<0.05 ;+p<0.01$.

\section{Results}

\section{Generalized Reciprocity}

Generalized reciprocity is evident when the victim recoups a loss by "paying it forward" to someone else. Operationally, we test generalized reciprocity by comparing the responses of those in the loss and no-loss conditions. Figure 1 displays the effects of experiencing a loss among links and seeds in the no-observation condition. The results show that the willingness to impose a loss on others is greater among victims of a loss, but the difference is statistically significant only among links. The logistic regressions in Table 1 confirm that the effect of loss is marginally non-significant for seeds $(p=0.065)$. However, the size of the effect is very similar for seeds $(b=1.542)$ and links $(b=1.482)$. Thus, the much larger standard error among seeds is likely due to the smaller number of observations. ${ }^{1}$ In short, links "did unto others as others had done unto them," but we cannot rule out the possibility that even those whose loss was imposed by chance also become more willing to pass that loss along to others as well.

\section{Third-Party Influence}

We tested the third-party influence hypothesis by comparing transfers in the noobservation condition (in which participants had no information about others' behavior) with two observation conditions (one with a low level of transfer by others and one with a high). This design distinguishes the effects of uncertainty (no information) from the effects of observing different normative behaviors. To isolate third-party influence from generalized reciprocity, we measured the effects of observation only among participants who did not experience a loss directly. Figure 2 shows the level of transfers among seeds and links who did not experience a loss, broken down by the level of transfer observed. The dashed line shows the level of transfers among participants in the no-observation condition. Compared to participants in the no-observation condition, those who are aware of the transfer behavior of others are slightly less likely to impose a loss on others, but the 
A) Seeds

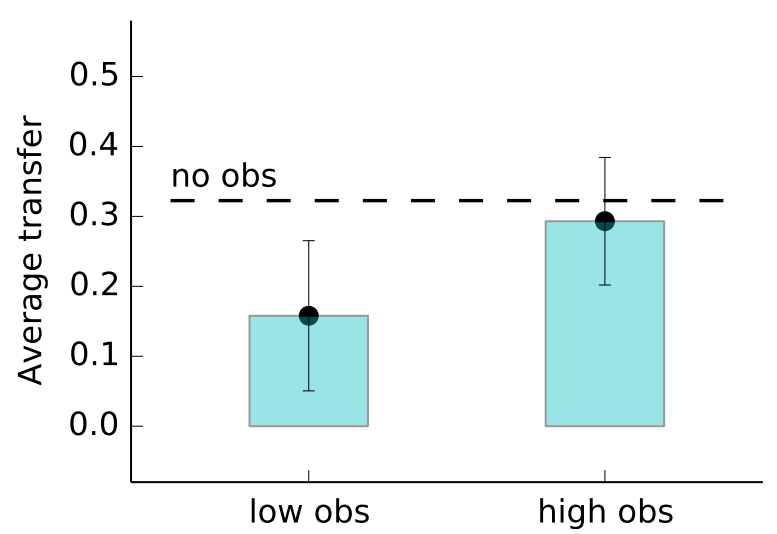

B) Links

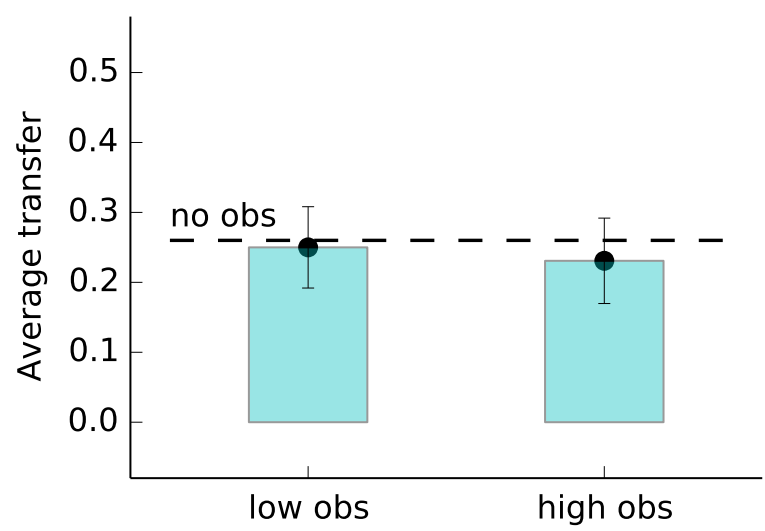

Figure 2: The effect of third-party influence on the amount transferred from the next participant. The figure shows the mean transfer rate and 95\% confidence interval for A) seeds and B) links with no loss. Compared to seeds in the no-observation treatment condition, seeds who observed low transfer levels had a significantly lower transfer rate but seeds who observed high transfer levels did not have higher transfer rates. This effect of observing the behavior of others is not evident among links.

difference is significant only among seeds who observe a low transfer level. This effect is confirmed by the corresponding logistic regressions reported in Table 2. The results also show a marginally non-significant difference between the low- and high-observation conditions $\left(\chi^{2}=3.26, p=0.071\right)$. The similarity in transfer behavior between the no-observation and high-observation conditions contradicts the broken windows hypothesis (Cialdini, Reno, and Kallgren 1990; Keizer, Lindenberg, and Steg 2008; see also Falk and Fischbacher 2002; Jordan et al. 2013), while the low transfer rate in the low-observation condition points instead to the positive effect of "unbroken windows," but only among seeds-those who were not themselves vulnerable to having their own windows broken. ${ }^{2}$

\section{Discussion}

Social contagion offers a compelling theoretical explanation for the spread of prosocial behavior (Tsvetkova and Macy 2014b). This study extends the investigation to the spread of antisocial behavior, using a controlled online experiment to test the independent effects of two contagion mechanisms-generalized reciprocity and third-party influence. We found similarities as well as important differences between prosocial and antisocial behavior in the effects of generalized reciprocity and third-party influence. Recipients of gifts as well as losses were more willing to pay it forward to a stranger, suggesting that the rule to "do unto others" does not require that the others are the same people who "did unto you." However, while a gift increases prosocial behavior compared to a chance windfall, a loss due to the malevolence of another person does not increase antisocial behavior compared to a 
Table 2: The effect of third-party influence on the amount transferred from the next participant.

\begin{tabular}{lcccc}
\hline & \multicolumn{2}{c}{ No Loss } & \multicolumn{2}{c}{ Loss } \\
& Seeds & Links & Seeds & Links \\
\hline Low observation & $-1.371^{*}$ & -0.080 & -0.908 & -0.378 \\
& $(0.620)$ & $(0.368)$ & $(0.862)$ & $(0.300)$ \\
High observation & -0.250 & -0.234 & -1.224 & -0.266 \\
Constant & $(0.532)$ & $(0.377)$ & $(0.890)$ & $(0.301)$ \\
& 0.598 & 0.080 & $2.140^{\dagger}$ & $1.562^{\dagger}$ \\
Number of observations & $(0.375)$ & $(0.283)$ & $(0.748)$ & $(0.216)$ \\
LR $\chi^{2}$ & 79 & 187 & 71 & 413 \\
\hline
\end{tabular}

Note:The table reports coefficients and standard errors (in parentheses) from logistic regressions for seeds and links without a loss and with a loss. Results show that observing a low level of transfers reduces the amount transferred but only among seeds who experienced no loss.

Two-sided tests: $* p<0.05 ;+p<0.01$.

loss due to random chance. Simply put, retaliation is not necessarily the flip side of reciprocity. This asymmetry corresponds to findings from studies on "loss aversion" and "attribution error" (Jones and Harris 1967; Ross 1977; Tversky and Kahneman 1991). An unexpected surplus does not in itself make us more generous, but an unexpected loss can induce efforts at recovery, whether or not the loss was caused by a deliberate choice by another person. It is possible that seeds experienced random gains as good fortune but random losses as transfers to the experimenter. We leave the exploration of these possibilities to future research.

Prosocial and antisocial behavior also differ in the response to observing the behavior of others. Compared to not observing, observing low levels of prosocial behavior increases the willingness to help others, but as the observed level increases, the bystander effect becomes increasingly evident. In contrast, observing low levels of antisocial behavior decreases the likelihood of harming others compared to not observing.

These differences in findings could also reflect an important difference in the designs of the prosocial and antisocial experiments. Tsvetkova and Macy's prosocial study (2014b) used repeated interactions, while the present study did not. The prosocial generalized reciprocity effect was largely within-individuals and may have reflected a self-interested response to the opportunity to benefit from the possibility that "what goes around may come around." The one-shot design in the antisocial study removed this possibility. Future research should explore whether repeated interaction weakens antisocial generalized reciprocity by posing the fear that harming others might increase the probability of being harmed in the future.

Future research is also needed to explore another condition that might strengthen the contagious properties of both prosocial and antisocial behavior. Researchers should manipulate the possibility for chains to branch, in order to measure the motivating effect of the opportunity for acts of generosity and harm to reverberate exponentially rather than linearly. For example, in the movie Pay It Forward, recip- 
ients of help were expected to help three other people. In both the experimental versions, recipients of help and harm could only pay it forward to one.

Future research should also replicate the study with participants with different demographic profiles in order to test whether the findings can be generalized beyond a population that was disproportionately young, well educated, white, from the United States, and male. The tendency to pay it forward in both the prosocial and antisocial situations may differ, for example, between collectivist and individualist cultures.

Further, the external validity of the study should be confirmed in a field experiment with stronger manipulations and more meaningful incentives, such as online multiplayer games or user-generated content communities that allow for anonymous interactions. These experiments would allow more socially meaningful measures of the effects of generalized reciprocity and third-party influence on the spread of antisocial behavior and of the practicality of possible interventions.

In contrast to the decision situation in our experiment, our everyday interactions are rarely anonymous and are often embedded in social context. In daily life, people indeed sometimes react to negative experiences by displacing their aggression; the expressions scapegoating and shooting the messenger describe such behavior. In general, however, pay-it-forward aggression is rarely arbitrary but rather targets role equivalents or subordinates. For example, employees abused by their supervisors are likely to be aggressive towards coworkers and subordinates at work or family members at home (Hoobler and Brass 2006). Among the indigenous American tribe Kwakiutl, mourners revenge the death of a loved one by killing someone whose rank is equivalent to the rank of the dead relative (Fiske and Rai 2014). Even among primates, low-ranked males who have lost to high-ranked males tend to attack females (Sapolsky 2006). Our experiment was conducted on random social interactions among anonymous peers, but future research should investigate whether antisocial behavior spreads similarly in existing hierarchical and/or clustered social networks.

With these caveats in mind, we conclude by calling attention to possible implications of our results for intervention strategies. For encouraging prosocial behavior, it has been suggested that third-party influence may be vital in the early stages of a contagion, by multiplying the number of cascades, while generalized reciprocity could be more beneficial in later stages, by offsetting the growing belief that one's own efforts are not needed as more people are observed to help others (Tsvetkova and Macy 2014b). The current results point to similar strategies for discouraging antisocial behavior. While generalized reciprocity can be self-reinforcing in the early stages of a contagion, third-party influence may prevent the further spread of antisocial behavior by reinforcing the fact that opportunistic behavior is rare.

\section{Notes}

1 The similarity in effect sizes for links and seeds is confirmed by the absence of a significant interaction between being a link and experiencing a loss, as reported in Table A3 in the online supplement. 
2 As with Table 1, the separate models for seeds and links who experience low and high loss can be aggregated as a model with two- and three-way interactions, none of which were statistically significant.

\section{References}

Bartlett, Monica Y. and David DeSteno. 2006. "Gratitude and Prosocial Behavior." Psychological Science 17:319-25. http://dx . doi .org/10.1111/j.1467-9280.2006.01705.x.

Bearman, Peter. 1997. “Generalized Exchange.” American Journal of Sociology 102:1383-415. http://dx.doi.org/10.1086/231087.

Ben-Ner, Avner, Louis Putterman, Fanmin Kong, and Dan Magan. 2004. "Reciprocity in a Two-Part Dictator Game." Journal of Economic Behavior E Organization 53:333-52. http://dx.doi.org/10.1016/j.jebo.2002.12.001.

Bond, Robert M., Christopher J. Fariss, Jason J. Jones, Adam D. I. Kramer, Cameron Marlow, Jaime E. Settle, and James H. Fowler. 2012. "A 61-Million-Person Experiment in Social Influence and Political Mobilization." Nature 489(7415):295-98. http: //dx. doi .org/10 . 1038/nature11421.

Centola, Damon. 2010. “The Spread of Behavior in an Online Social Network Experiment." Science 329(5996):1194-7. http: //dx . doi . org/10.1126/science.1185231.

Christakis, Nicholas A. and James H. Fowler. 2009. Connected: The Surprising Power of Our Social Networks and How They Shape Our Lives. New York: Little, Brown and Company.

Cialdini, Robert B. 2008. Influence: Science and Practice. Boston: Allyn \& Bacon.

Cialdini, Robert B., Raymond R. Reno, and Carl A. Kallgren. 1990. “A Focus Theory of Normative Conduct: Recycling the Concept of Norms to Reduce Littering in Public Places." Journal of Personality and Social Psychology 58(6):1015-26. http://dx . doi .org/ 10.1037/0022-3514.58.6.1015.

Ekeh, Peter P. 1974. Social Exchange Theory: The Two Traditions. Cambridge, MA: Harvard University Press.

Fagan, Jeffrey, Deanna L. Wilkinson, and Garth Davies. 2007. "Social Contagion of Violence." Pp. 688-723 in The Cambridge Handbook of Violent Behavior, edited by D. Flannery, A. Vazsonyi, and I. Waldman. Rochester, NY: Cambridge University Press.

Falk, Armin and Urs Fischbacher. 2002. "'Crime' in the Lab-Detecting Social Interaction." European Economic Review 46(4-5):859-69. http://dx.doi.org/10.1016/ S0014-2921 (01)00220-3.

Fiske, Alan Page and Tage Shakti Rai. 2014. Virtuous Violence. Cambridge, UK: Cambridge University Press. http://dx.doi.org/10.1017/CB09781316104668.

Fowler, James H. and Nicholas A. Christakis. 2010. “Cooperative Behavior Cascades in Human Social Networks." Proceedings of the National Academy of Sciences 107(12):5334-8. http://dx.doi.org/10.1073/pnas.0913149107.

Greiner, Ben and M. Vittoria Levati. 2005. "Indirect Reciprocity in Cyclical Networks: An Experimental Study." Journal of Economic Psychology 26:711-731. http://dx . doi .org/10 . $1016 / j \cdot j$ oep. 2004.04 .003$.

Hoobler, Jenny M. and Daniel J. Brass. 2006. "Abusive Supervision and Family Undermining As Displaced Aggression." Journal of Applied Psychology 91(5):1125-33. http://dx . doi . org/10.1037/0021-9010.91.5.1125. 
Jones, Edward E. and Victor A. Harris. 1967. "The Attribution of Attitudes." Journal of Experimental Social Psychology 3(1):1-24. http://dx.doi.org/10.1016/0022-1031 (67) 90034-0.

Jones, Marshall B. and Donald R. Jones. 2000. “The Contagious Nature of Antisocial Behavior." Criminology 38(1):25-46. http: //dx . doi .org/10.1111/j.1745-9125.2000.tb00882 .x.

Jordan, Jillian J., David G. Rand, Samuel Arbesman, James H. Fowler, and Nicholas A. Christakis. 2013. "Contagion of Cooperation in Static and Fluid Social Networks." PLoS ONE 8(6):e66199. http://dx.doi .org/10.1371/journal . pone.0066199.

Keizer, Kees, Siegwart Lindenberg, and Linda Steg. 2008. "The Spreading of Disorder." Science 322(5908):1681-85. http://dx . doi .org/10.1126/science.1161405.

Keizer, Kees, Siegwart Lindenberg, and Linda Steg. 2013. “The Importance of Demonstratively Restoring Order." PLoS ONE 8(6):e65137. http://dx.doi .org/10.1371/journal. pone. 0065137.

Lawler, Edward J. 2001. "An Affect Theory of Social Exchange." American Journal of Sociology 107(2):321-52. http://dx.doi.org/10.1086/324071.

Loftin, Colin. 1986. "Assaultive Violence As a Contagious Social Process." Bulletin of the New York Academy of Medicine 62(5):550-55.

Malinowski, Bronislaw. 1920. "51. Kula; The Circulating Exchange of Valuables in the Archipelagoes of Eastern New Guinea." Man 20:97-105. http://dx .doi .org/10. 2307/ 2840430.

Molm, Linda D. 2010. "The Structure of Reciprocity." Social Psychology Quarterly 73(2):119-31. http://dx.doi.org/10.1177/0190272510369079

Molm, Linda D., Jessica L. Collett, David R. Schaefer. 2007. “Building Solidarity through Generalized Exchange: A Theory of Reciprocity." American Journal of Sociology 113:205-42. http://dx.doi.org/10.1086/517900.

Muchnik, Lev, Sinan Aral, and Sean J. Taylor. 2013. "Social Influence Bias: A Randomized Experiment." Science 341(6146):647-51. http://dx . doi .org/10.1126/science. 1240466.

Nowak, Martin A. and Sébastien Roch. 2007. "Upstream Reciprocity and the Evolution of Gratitude." Proceedings of the Royal Society B 274:605-10. http://dx.doi .org/10.1098/ rspb. 2006.0125.

Nowak, Martin A. and Karl Sigmund. 2005. "Evolution of Indirect Reciprocity." Nature 437:1291-8. http://dx.doi.org/10.1038/nature04131.

Raub, Werner and Jeroen Weesie. 1990. "Reputation and Efficiency in Social Interactions: An Example of Network Effects." American Journal of Sociology 96(3):626-54. http: //dx.doi.org/10.1086/229574.

Rogers, Everett M. 2003. Diffusion of Innovations. New York: Free Press.

Ross, Lee. 1977. "The Intuitive Psychologist and His Shortcomings: Distortions in the Attribution Process." Advances in Experimental Social Psychology 10:173-220. http://dx . doi .org/10.1016/S0065-2601 (08)60357-3.

Salganik, Matthew J., Peter Sheridan Dodds, and Duncan J. Watts. 2006. “Experimental Study of Inequality and Unpredictability in an Artificial Cultural Market." Science 311(5762):8546. http://dx.doi.org/10.1126/science.1121066.

Sapolsky, Robert M. 2006. "Culture in Animals: The Case of a Non-Human Primate Culture of Low Aggression and High Affiliation." Social Forces 85(1):217-33. http://dx.doi. org/10.1353/sof.2006.0142. 
Seinen, Ingrid and Arthur Schram. 2006. "Social Status and Group Norms: Indirect Reciprocity in a Repeated Helping Experiment." European Economic Review 50(3):581-602. http://dx.doi.org/10.1016/j.euroecorev.2004.10.005.

Stanca, Luca. 2009. "Measuring Indirect Reciprocity: Whose Back Do We Scratch?" Journal of Economic Psychology 30:190-202. http://dx.doi.org/10.1016/j . joep. 2008.07.010.

Suri, Siddharth and Duncan J. Watts. 2011. "Cooperation and Contagion in Web-Based, Networked Public Goods Experiments." PLoS ONE 6(3):e16836. http://dx.doi .org/10 . 1371/journal.pone.0016836.

Sutherland, Edwin Hardin and David Luckenbill. 1992. Principles of Criminology. Dix Hills, NY: General Hall.

Tsvetkova, Milena and Vincent Buskens. 2013. "Coordination on Egalitarian Networks from Asymmetric Relations in a Social Game of Chicken." Advances in Complex Systems 16:1350005. http://dx.doi.org/10.1142/S0219525913500057.

Tsvetkova, Milena and Michael W. Macy. 2014a. "The Science of 'Paying It Forward."' The New York Times, March 14.

Tsvetkova, Milena and Michael W. Macy. 2014b. "The Social Contagion of Generosity." PLoS ONE 9(2):e87275. http://dx.doi.org/10.1371/journal . pone.0087275.

Tversky, Amos and Daniel Kahneman. 1991. "Loss Aversion in Riskless Choice: A ReferenceDependent Model." The Quarterly Journal of Economics 106(4):1039-61. http://dx. doi . org/10.2307/2937956.

Uehara, Edwina. 1990. "Dual Exchange Theory, Social Networks, and Informal Social Support." American Journal of Sociology 96:521-57. http://dx. doi .org/10.1086/229571.

Wedekind, Claus and Manfred Milinski. 2000. “Cooperation through Image Scoring in Humans." Science 288(5467):850-52. http://dx.doi .org/10.1126/science. 288.5467. 850.

Widom, Cathy S. 1989. "Does Violence Beget Violence? A Critical Examination of the Literature." Psychological Bulletin 106(1):3-28. http://dx.doi.org/10.1037/0033-2909. 106.1.3.

Wilson, James Q. and George L. Kelling. 1982. “Broken Windows.” Atlantic Monthly 249(3):2938.

Yamagishi, Toshio and Karen S. Cook. 1993. "Generalized Exchange and Social Dilemmas." Social Psychology Quarterly 56:235-48. http://dx.doi .org/10.2307/2786661.

Acknowledgements: This work was supported by grants SES-1260348 and SES-1303526 from the National Science Foundation and by NRF-2013S1A3A2055285 from the National Research Foundation of Korea.

Milena Tsvetkova: Department of Sociology, Cornell University. E-mail: mvt9@cornell.edu.

Michael W. Macy: Department of Sociology and Department of Information Science, Cornell University. E-mail: m.macy@cornell.edu. 